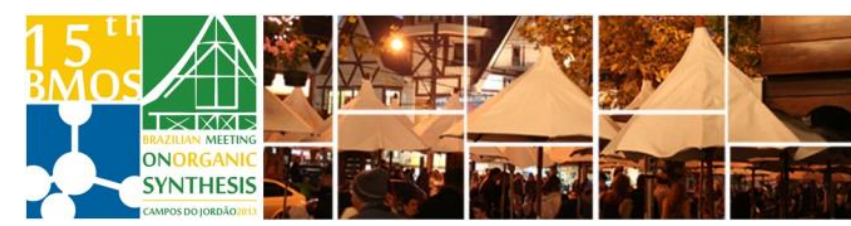

\title{
Cyclization of Homoallylic Alcohols with lodine/lodine(III)
}

\author{
Paulo Scarassati and Luiz F. Silva Jr.* \\ Instituto de Química, USP, CP 26077, CEP 05513-970, São Paulo SP, Brazil \\ scarpaulo@hotmail.com and *luizfsjr@iq.usp.br
}

Keywords: Homoallylic Alcohols, Cyclization, Hypervalent lodine, Tetrahydrofurans

\section{INTRODUCTION}

There is a great interest in the synthesis of substituted tetrahydrofurans, because they are present in many biological activity compounds. ${ }^{1}$ THF compounds can be obtained by cyclofunctionalization of homoallylic alcohols. ${ }^{1}$ Many electrophiles have been used, such as halogens, thallium(III), mercury(II), selenium, etc. ${ }^{1}$

The iodocyclization of homoallylic alcohols with terminal double bonds leads to the formation of oxetanes. $^{2}$ This happens because the 5-endo-trig cyclization is not favored for this type of substrate. An alternative protocol was developed by our group. ${ }^{3}$ The use of hypervalent iodine with a catalytic amount of molecular iodine facilitates the formation of tetrahydrofurans rings from homoallylic alcohols. The proposed mechanism (Scheme 1) ${ }^{3}$ consists mainly in the oxidative displacement of iodine from alkyl iodides and the ring expansion of cyclic ethers having an iodoalkyl substituent. In previous work, the reaction was explored with tertiary alcohols. In this study, we expanded the scope of the reaction for primary and secondary alcohols.
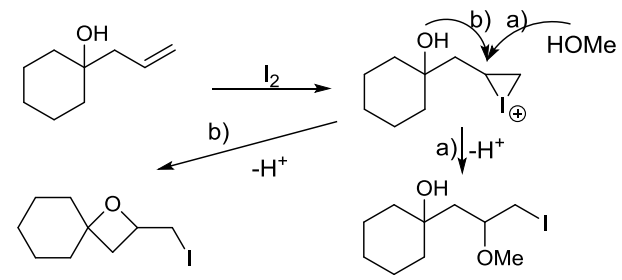

$\mathrm{DIB} \mid-\mathrm{Phl}$

$\mathrm{DIB} \downarrow-\mathrm{PhI}$
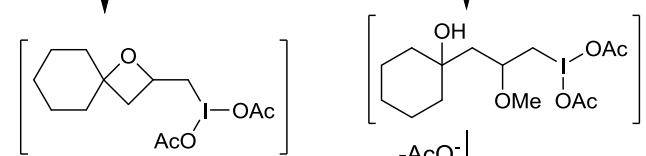

$-\mathrm{AcO}^{-} \downarrow$

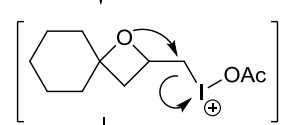

-AcOI $\downarrow_{\oplus}$ HOMe

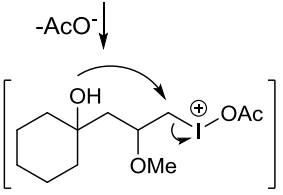

$-\mathrm{AcOI} \downarrow-\mathrm{H}^{+}$
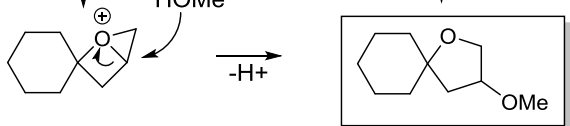

Scheme 1. Proposed Mechanism of lodine/lodine(III) cyclization

\section{RESULTS AND DISCUSSION}

The starting materials 1a-c were prepared by Grignard reaction using allyl magnesium bromide and the corresponding aldehyde. The substrate 1d was prepared from the opening of styrene epoxide by vinyl magnesium bromide, whereas $1 \mathrm{e}$ is commercially available. The reaction of the homoallylic alcohols 1ae with $\mathrm{HTIB}(\mathrm{Phl}(\mathrm{OH}) \mathrm{OTs})$ and $\mathrm{I}_{2}$ led to the formation of the desired products (Table 1). This reaction can be easily monitored by color change (Figure 1).

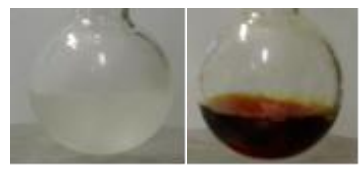

Figure 1. Color before and after the reaction completion

Table 1. Reaction of 1a-e with $\mathrm{I}_{2} / \mathrm{HTIB}$

Entry

\section{CONCLUSION}

This methodology can serve well for obtaining substituted tetrahydrofurans starting from primary and secundary homoallylic alcohols.

\section{ACKNOWLEDGEMENTS}

FAPESP, CNPq and CAPES for financial support.

\section{REFERENCES}

1 Jalce, G.; Franck, X.; Figadére, B. Tetrahedron: Asymmetry 2009, 20 2537. ${ }^{2}$ Evans, R. D.; Magee, J. W.; Schauble, J. H. Synthesis 1988, 11 862. ${ }^{3}$ Vasconcelos, R. S.; Silva, L. F., Jr; Giannis, A. J. Org. Chem., 2011, 761499. 